\title{
A Modified PI Control for Grid-tied Inverters to Improve Grid Injected Current Quality
}

\author{
P. Rajesh ${ }^{\# 1}$, Ram Ishwar Vais ${ }^{\# 2}$, Shivam Yadav ${ }^{\# 3}$, Parag Swarup ${ }^{\# 4}$

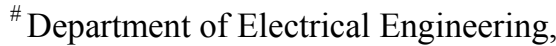 \\ Institute of Engineering \& Technology, Lucknow, 226021, India. \\ ${ }^{1}$ rajeshcoo1250@gmail.com, ${ }^{2}$ ramismdhanbad@gmail.com \\ ${ }^{3}$ shivammyadavv@gmail.com, ${ }^{4}$ paragswarup04@gmail.com
}

\begin{abstract}
The injection of good quality current into the grid is always prominent task for the grid-tied inverters. The usage of classical Proportional Integral (PI) controllers, though, dominates in all process control industry, they fail to track periodic signals like sine waves without DQ transformations. To eliminate the usage of DQ coordinates and also the steady state error in sinusoidal signals tracking, the sinusoidal error input feeding to the PI controller is divided into $\mathrm{N}$-step shaped single. The value of $\mathrm{N}$ is decided by the switching frequency used in the controller loop, to eliminate the dead-zone effect of inverter switches. Mathematical analysis and extensive simulation results are proved that elimination of steady state error and injection of good quality of sinusoidal current when compared to Conventional PI controller. The THD analysis clearly approves the outperformance of the modified PI controller over the conventional one.
\end{abstract}

Keyword - Current control, feed-forward, grid-tied inverters, PI controllers, Steady state error, Steady-state error, Total Harmonic Distortion

\section{INTRODUCTION}

Modern power grid and utility supplies are highly equipped with distributed energy sources and power electronics converter devices for the reliable power control flow between the loads and supply sources [1]. Among these converters, grid-tied inverters plays prominent role in maintaining the good quality of current injection to the grid from available DC sources like Photovoltaic panels, Fuel cells etc.[2-4]. The quality of the injected power is decided based on the injected current by the grid-tied inverter. To decide the quality of the electrical signal in power system, THD is taken as the performance index. This index depicts the magnitude of the fundamental component when compared with the all remaining higher order frequency components in the particular waveform or signal. THD of the injected current influences the grid system efficiency, in the sense, higher the current harmonic distortion, lesser the efficiency of the system. [5]. Hence, the IEEE1547 states that the system with current harmonic distortion garter than $5 \%$ is strictly not allowable. Inappropriate usage of controllers used for the inverter lead to the significant reason for THD. Generally PI controllers are very dominant and versatile controller for lot many industrial applications. But, the same conventional PI controller cannot track the periodic signals like sinusoidal waveforms. Hence, special treatment is much needed before using this controller for the usage of sinusoidal signal tracking.

In conventional control technology, the grid tied inverters uses the feedback control method. In this method, the injected current is sinusoidal wave and its reference is also sinusoidal one, hence the error is also results in the same shape. This sinusoidal error has to be eliminated with the appropriate control strategy to track the desired injected current from the inverter to the grid. There are different types of control strategies existed in the literature, like- hysteresis controller[6], PI controller, H-infinity controller[7], proportional resonant controller[8], repetitive controller [9],[10], dead beat controllers[11],[12] etc. The best way, to track the proper sinusoidal current, is the usage of hysteresis controller. Though, its implementation is easy and more robust towards the source and load changes, it produces variable switching frequencies to the inverter switches. This leads to the difficulty in efficient selection of L,C values for inverter filter design.[13-15]. The traditional PI controller never tracks the time varying signals with no steady state error. H-infinity controller again be the good quality controller, but the implementation will be difficult, due to its higher order structure. Proportional Resonant controllers have the satisfied performance in steady state, but any change in the grid frequency, may cause adverse effects on the performance of it. Repetitive controller is the most sophisticated controller for tracking repetitive periodic signals like sinusoidal waveforms. But, it requires the model for interference signal to include in the controller.[16-18]. Besides, there are nonlinear controllers used for inverter current control[19]. Due to less availability of mathematical analysis, these nonlinear controllers are also risk to use in real applications. 
Hence, the proposed work uses the most versatile structured PI controller with small modifications, widely used in $60 \%$ industrial applications[20], for tracking sinusoidal injected current tracking, by dividing error into $\mathrm{N}$ number of stepped wave form. The remaining paper is organized as follows: Section II, describes the working of the conventional PI controller with the inverter and also proves that it cannot eliminate the steady-state error for periodic signals. The modifications to the present PI controller are proposed in section III. The simulation steady has done for showing the out performance of the modified PI controller by tracking the grid reference current in section IV and finally, conclusions are drawn in section V.

\section{GRID-TIED INVERTER WITH CONVENTIONAL PI CONTROLLER}

The schematic diagram of the grid-tied inverter, with the current signal as feedback for the controller to generate the required pulse D to the inverter switches, is shown in Fig. 1. In the present work, closed loop current control uses the PI based controller along with the feedforward link to inject the required power demanded by loads.

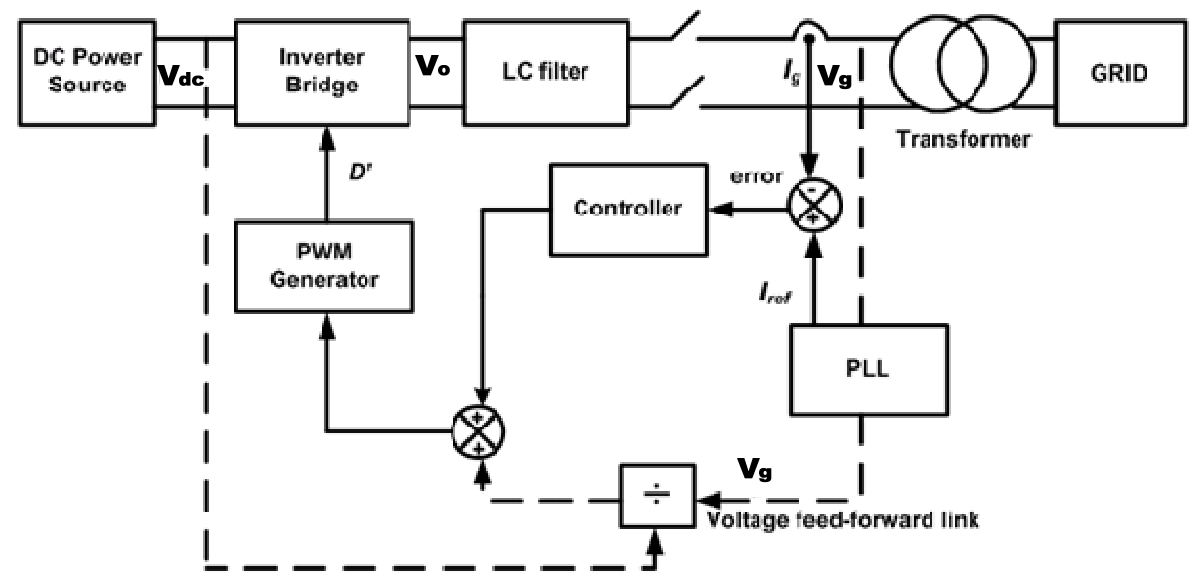

Fig. 1. Structure of grid connected Inverter

The Assume that DC link voltage at the input terminals of the inverter as $V_{d c}$, and duty cycle to the inverter as D' and voltage at the output terminal of the inverter $V_{o}$. Based on Equivalent Areas principle, the above three variables are related as below,

$V_{o}=V_{d c} \times \mathrm{D}^{1}$

To send the power always from source to grid, the inverter output voltage always greater than the grid voltage, Vg. The output voltage from the inverter is constructed form the two components :one component used to create the grid offset voltage, the another part is useful to maintain the desired injected current. Hence, the duty cycle also having the two parts as shown in (2)

$V_{o}=V_{d c} \times\left(\frac{V_{g}}{V_{d c}}+D\right)=V_{g}+V_{d c} \times D$

To further simplify the model of the closed loop system, grid voltage can be excluded by incorporating the feedforward coefficient as $1 / \mathrm{Vdc}$. so that open loop transfer function of the system is free from the Vg. Hence the total system closed loop block diagram as shown in Fig. 2.

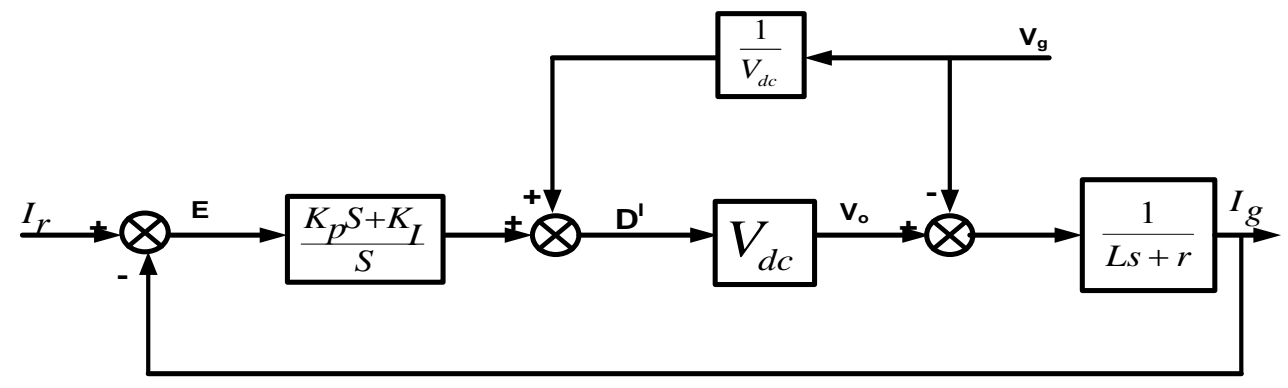

Fig. 2. Closed-loop System with PI controller 
From the Fig. 2., the open-loop transfer function of the system has been modified as follows,

$$
L(s)=\frac{\left(K_{P} \times S+K_{P}\right) \times V_{d c}}{S(S L+r)}
$$

From (3), it reveals that the above system represents the type-1 system, hence there is always a steady-state error when the type-I system tracks a periodic signal.

\section{GRID-TIED INVERTER WITH CONVENTIONAL PI CONTROLLER}

The output of the conventional PI controller, which is also known as Control effort $\left(U_{e}\right)$ in control terminology, is given as;

$U_{e}=K_{P} \times e(t)+\int K_{t} \times e(t) d t$

Where, e $(\mathrm{t})$ is the error signal generated from reference current signal and actual injected current signal.

The inverter closed loop system with PI controller is type - 1 system, Hence the idea, to avoid the steady state error from the periodic signals with this existed system, is to split the periodic signal into stepped waveform. Hence the error, which is a periodic signal divided into several samples of step signals and do proportional and integration of the same phase samples at each time. With this scheme, PI will view the sinusoidal current signal as a set of multiple step signals; which can easily makes the elimination of steady state error in the injected current signal. Moreover, the N stepped switching waves are collectively forms one full fundamental sine wave form, hence the duty cycle for the inverter switches is also fixed at each and every sample of the fundamental signal generated by the inverter. This may also give the freedom to the controller designer, to compare the same phase signal in the reference wave to the same phase signal in the actual current wave from, so that it excludes the effects caused by dead times of inverter switches. Thus, the final modified PI implemented in the simulation, will produces $U_{e}$ as shown below:

$U_{e}=K_{P} \times e(k)+K_{I} \times[e(k)+e(k-1)+e(k-2)+\ldots \ldots . .+e(0)]$

The equation (5), clearly, shows that PI controller produces the control effort $U e$ by processing the errors at different phase angles whose instants are decided by the value of steps $(N)$ considered for the dividing periodic waveform. Hence the duty cycle/ control effort $U_{e}$ obtained from the PI controller for the corresponding N-step Input error, without any steady error. Further any correction signal is required to eliminate further magnitude errors in each phase of the error signal, there is iterative integrating path with attenuation gain added in that path. Hence, the this arrangement will make the further production of corrective signal $U_{e p}$, until there is complete elimination of error corresponding each N-step reference and actual current signal. So, this further cumulative integration inside the current cycle completely eliminates the steady state error to zero, after few fundamental cycles.

$U_{e p}=K_{P} \times e(k)+K_{I} \times\left\lfloor e_{p}(k)+k \times e_{p}(k-1)+k^{2} \times e_{p}(k-2)+\ldots \ldots . .+k^{2} \times e_{p}(0)\right\rfloor$

$U_{e p}$ represents the correction signal corresponding to the each phase angle point $p$ in present periodic cycle, $e_{P}(k)$.is the error magnitude at the processed phase point $p(p=1,2, \ldots \mathrm{N})$ in the present fundamental cycle, $\left(e_{P}(k-1), e_{P}(k-2), \ldots e_{P}(0)\right)$ are the error signals in previous cycles at the same phase point p. $K_{P}$ and $K_{I}$ represents the proportional and integral coefficients of same PI controller respectively.

\section{IV.GRID-TIED INVERTER WITH CONVENTIONAL PI CONTROLLER}

To check and realise the performance of the above proposed PI control method, a foxed-step MATLAB/SIMULINK environment is created. Inverter is realised with Fast switching IGBTs which can operate at $20 \mathrm{KHz}$. A low pass LC filter is attached to filter out the all switching frequency harmonics from the output voltage of the switched base inverter. Whole closed loop simulation is done using fixed step solver to replicate the real time closed loop simulations. And more over, controller also discretised using zero order hold blocks. The system parameters used for the simulation are listed in Table I. The proposed modified PI controller for inverter application is shown in Fig. 3. Here, authors are using sampling frequency of $36000 \mathrm{~Hz}$ for the controller, which results in 720 samples $(=36000 / 50)$ for one cycle of sinusoidal waveform. Each 720 samples added with corresponding samples in each cycle to nullify the steady state error to zero. The $K_{P}$ and $K_{I}$ values are chosen as 15.6 and 12.0, respectively. The implementation of PI structure in the simulation is followed the well-known parallel-PID structure. The attenuation coefficient $K$ is taken as 0.8 . To synchronize the reference current command $\left(i_{r e f}\right)$ with the grid voltage $\left(V_{g}\right)$, the Phase angel is retrieved from the gird the voltage signal. For generating the PWM Signal from the output of the proposed controller, a triangular of $20 \mathrm{KHz}$ signal is generated. 
TABLE I Simulation Parameters for inverter with modified PI method

\begin{tabular}{|l|l|}
\hline Parameters & Numerical value \\
\hline DC supply $\boldsymbol{U}_{\mathrm{dc}}$ & $400 \mathrm{~V}$. \\
\hline System frequency $f_{s}$ & $50 \mathrm{~Hz}$ \\
\hline Switching frequency $f_{s w}$ & $20 \mathrm{kHz}$ \\
\hline Sampling frequency $f_{\text {sample }}$ & $36 \mathrm{kHz}$ \\
\hline Inductance $L_{f}$ & $2.4 \mathrm{mH}$ \\
\hline Capacitor $C_{f}$ & $2.2 \mu \mathrm{F}$ \\
\hline Load resistance $R_{o}$ & $11.5 \Omega$ \\
\hline Grid voltage $\boldsymbol{U}_{N}$ & $230 \mathrm{~V}$ \\
\hline
\end{tabular}

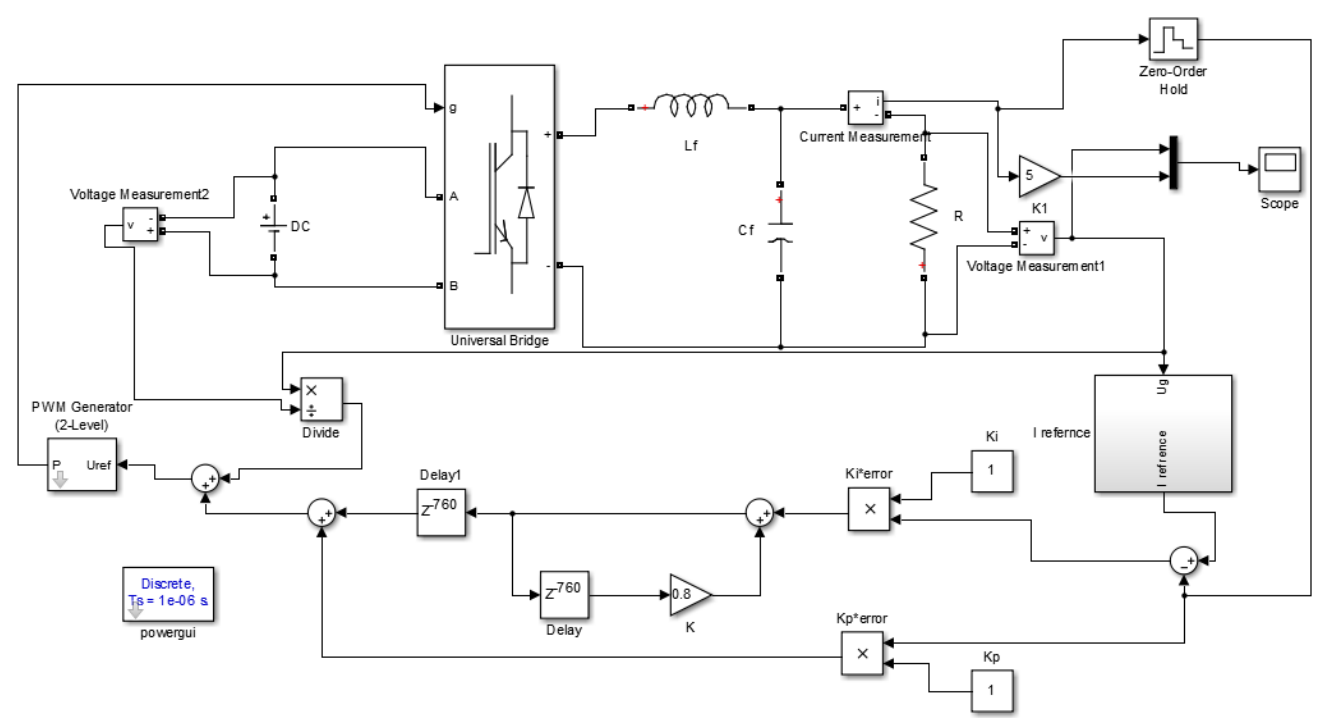

Fig. 3. Fixed-step MATLAB simulation environment for grid connected inverter

Fig. 4. shows the grid voltage and grid collected current by the inverter operated with conventional PI controller for error tracking. Fig. 5. shows the grid voltage and grid collected current by the inverter with novel PI controller for error tracking. The Fig. 4. clearly shows the grid current ripple changing from the value $80 \mathrm{~A}$ to $100 \mathrm{~A}$. But, in proposed Modified method, the grid injected current has almost zero ripple in the wave form signal which has clearly shown in zoomed view in Fig. 5. The THD analysis for both controlling methods are shown in Fig. 6., which proves that novel PI controller method improves the quality of injected current to the grid.

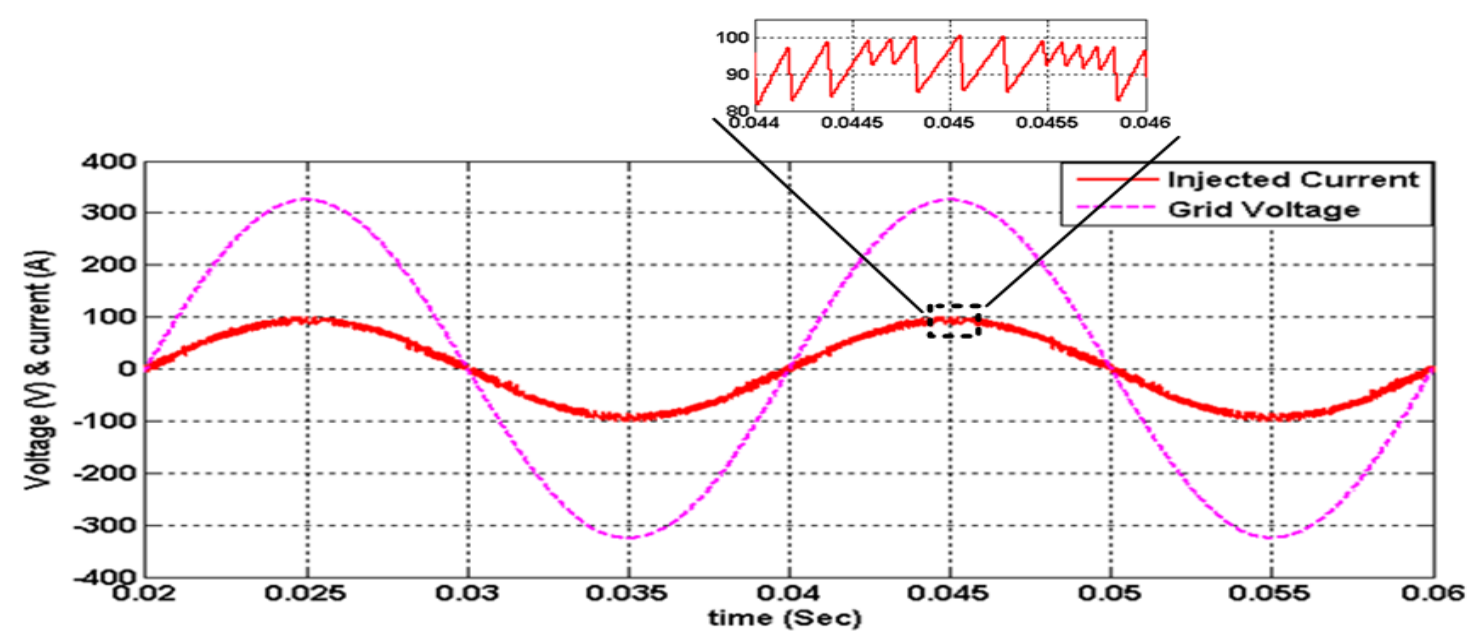

Fig. 4. Grid voltage and injected current (scaled to 5) with conventional PI method 


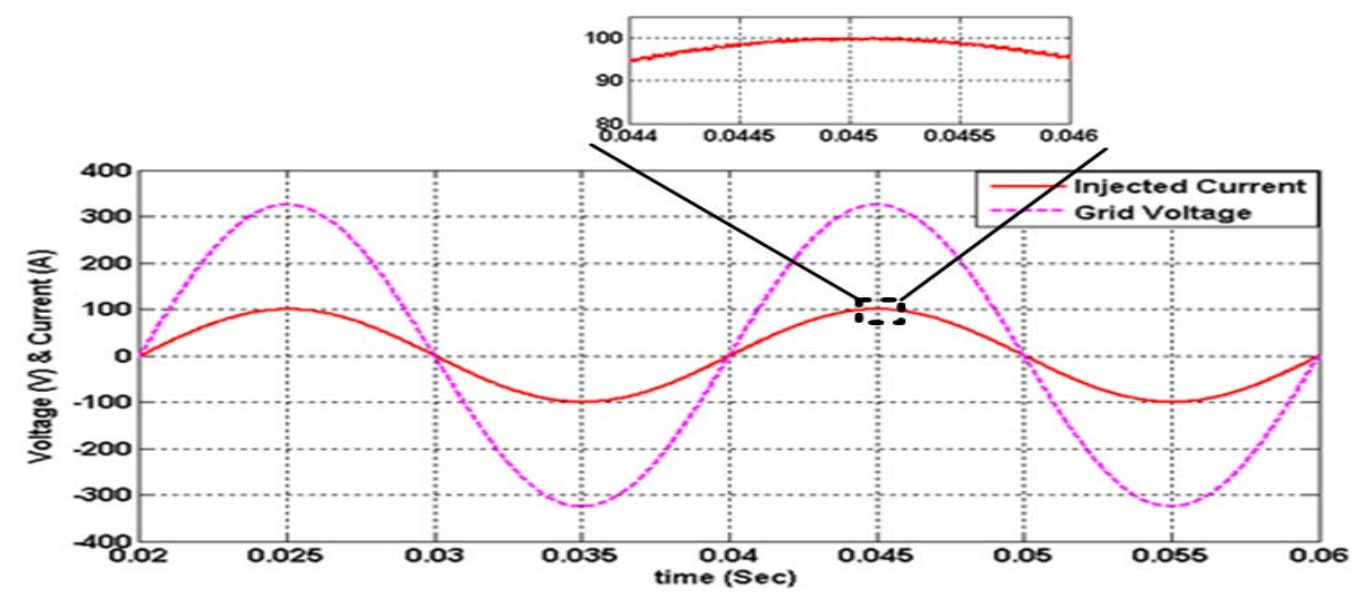

Fig. 5. Grid voltage and injected current (scaled to 5) with modified PI method

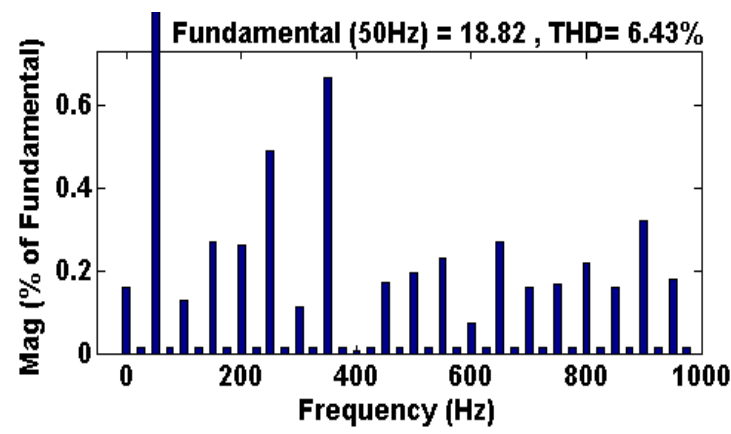

(a)

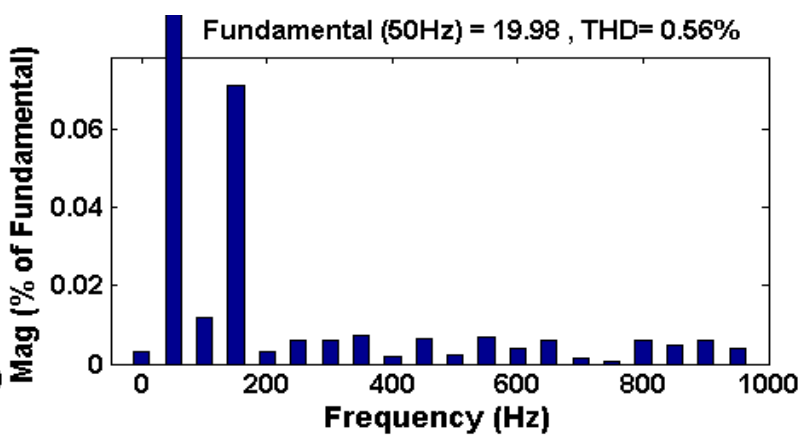

(b)

Fig. 6. THD analysis of grid collected current with a) conventional and b) modified PI methods

\section{CONCLUSION}

In this paper, modification of PI controller has been proposed to eliminate the steady state error while tracking the periodic signals. The modified PI has been tested with the grid-tied inverter application. Dividing the periodic signal into the N-Stepped wave signals and cumulative integration after the current cycle integration with the attenuation factor, makes the present proposal succeed in elimination of steady-state error in the sinusoidal signal. The extensive MATALB/ SIMULINK simulation results and THD analysis proves the quality of improved periodic signal tracking with the modified PI controller over the traditional PI controller. This method can be used for tracking the any type periodic signals without using DQ co-ordinates.

\section{REFERENCES}

[1] Yang Zhou and C. Ngai-Man Ho, "A review on Microgrid architectures and control methods", IEEE 8th International Power Electronics and Motion Control Conference (IPEMC-ECCE Asia), Hefei, 2016, pp. 3149-3156.

[2] W. Xiao, M. S. El Moursi, O. Khan and D. Infield, "Review of grid-tied converter topologies used in photovoltaic systems", IET Renewable Power Generation, vol. 10, no. 10, pp. 1543-1551, 2016.

[3] S Y. Tang, L. Huang and G. Zhao, "Resonant feed forward control for LCL-type grid-tied inverters in weak grid condition", IEEE Energy Conversion Congress and Exposition (ECCE), Milwaukee, WI, 2016, pp. 1-6.

[4] N. Mahmud; A. Zahedi; A. Mahmud, "A cooperative operation of novel PV inverter control scheme and storage energy management system based on ANFIS for voltage regulation of grid-tied PV system", IEEE Transactions on Industrial Informatics, vol. PP, no.99, pp.1-1.

[5] R. G. Wandhare and V. Agarwal, "A novel technique for THD control in grid connected Photovoltaic systems using step variable inductor approach”, 35th IEEE Photovoltaic Specialists Conference, Honolulu, HI, 2010, pp. 002844-002848.

[6] A. Timbus, M. Liserre, R. Teodorescu, P. Rodriguez and F. Blaabjerg, "Evaluation of Current Controllers for Distributed Power Generation Systems", IEEE Transactions on Power Electronics, vol. 24, no. 3, pp. 654-664, March 2009.

[7] Z. Li, C. Zang, P. Zeng, H. Yu, S. Li and J. Bian, "Control of a Grid-Forming Inverter Based on Sliding-Mode and Mixed $\$\left\{\mathrm{H}_{-} 2\right\} /\left\{\mathrm{H} \_\right.$infty $\}$\$ Control”, IEEE Transactions on Industrial Electronics, vol. 64, no. 5, pp. 3862-3872, May 2017

[8] Sera, D., Kerekes, T., Lungeanu, M., Nakhost, P., Teodorescu, R., Andersen, G.K. and Liserre, M., "Low-Cost Digital Implementation of Proportional-Resonant Current Controllers for PV Inverter Applications Using Delta Operator.", Industrial Electronics Society, 31st Annual Conference of IEEE, 2005

[9] Q. Zhao; Y. Ye, "A PIMR-type Repetitive Control for a Grid-tied Inverter: Structure, Analysis, and Design", IEEE Transactions on Power Electronics, vol.PP, no.99, pp.1-1.

[10] N. Marati; D. Prasad, "A Modified Feedback Scheme Suitable for Repetitive Control of Inverter With Non-Linear Load", IEEE Transactions on Power Electronics, vol.PP, no.99, pp.1-1.

[11] Mohamed, Y.A.-R.I. and El-Saadany, E.F., "Robust High Bandwidth Discrete-Time Predictive Current Control with Predictive Internal Model-A Unified Approach for Voltage-Source PWM Converters", IEEE Trans, Power Electronics, vol.23, no.1, pp.126136, Jan 2008. 
[12] Moreno, J.C., Huerta, J.M.E., Gil, R.G. and Gonzalez, S.A. ,"A Robust Predictive Current Control for Three-Phase Grid-Connected Inverters", IEEE Trans, Industrial Electronics, vol.56, no.6, pp.1993-2004, Jun 2009.

[13] George, V. and Mishra, M.K., "Design and Analysis of User-Defined Constant Switching Frequency Current Control based Four Leg DSTATCOM.”, IEEE Trans Power Electronics, vol.24, no.9, pp.2148-2158, Sep.2009

[14] Ho, C.N.-M., Cheung, V.S.P. and Chung, H.S.-H., "Constant-Frequency Hysteresis Current Control of Grid-Connected VSI Without Bandwidth Control.” IEEE Trans Power Electronics, vol.24, no.11, pp.2484-2495, Nov 2009.

[15] Yao, Z. and Xiao, L., "Two-Switch Dual-Buck Grid-Connected Inverter With Hysteresis Current Control." IEEE Trans Power Electronics, vol.27, no.7, pp. 3310-3318, Jul 2012

[16] Weiss G., Qing-Chang Zhong, Green T.C., Jun Liang, "Hळ repetitive voltage control of grid-connected inverters with a frequency adaptive mechanism.”, IEEE Trans Power Electronics, vol. 19, no. 1, pp. 219-230, Jan 2004.

[17] Bin Zhang, Danwei Wang, Keliang Zhou, and Yigang Wang, "Linear Phase Lead Compensation Repetitive Control of a CVCF PWM Inverter," IEEE Trans Industrial Electronics, vol.55, no.4, pp.1595-1602, Apr 2008.

[18] Escobar, G., Hernandez-Briones, P.G., Martinez, P.R., Hernandez-Gomez, M. and Torres-Olguin, R.E. “A Repetitive-Based Controller for the Compensation of $61 \pm 1$ Harmonic Components",Industrial Electronics, vol.55, no.8, pp.943-952, Aug 2008.

[19] Hao Ma and Siliang Han, "Buck inverter with sliding mode control strategy,"30th Annual Conference of IEEE Industrial Electronics Society, 2004. IECON 2004, 2004, pp. 592-597 Vol. 1.

[20] Jingqing Han, "From PID to Active Disturbance Rejection Control," IEEE Transactions on Industrial Electronics, vol.56, no.3, pp.900906, March 2009.

\section{AUTHOR PROFILE}

Ram Ishwar Vais He has completed his B.Tech and M.Tech degrees from Dr. K.N.M. Institute of Engineering \& Technology, Modinagar and ISM Dhanbad, respectively. He is currently working in I.E.T. Lucknow in Electrical Engineering department. His area of research interests includes Reactive Power Control, Optimization Techniques.

Shivam Yadav He received his B.Tech and M.Tech degrees from Dr. K.N.M. Institute of Engineering \& Technology, Modinagar and ISM Dhanbad, respectively. He is also currently working in I.E.T. Lucknow in Electrical Engineering department. His research interests includes the renewable energy applications and power Electronics converters Applications.

Parag Swarup He received his B.Tech and M.Tech degrees from Shree ram murty smarak college of Engineering \& Technology, Bareilly and NIT kurukshetra, respectively. He is currently working in I.E.T. Lucknow in Electrical Engineering department. His research interests includes the renewable energy applications and power Electronics converters Applications. 